\title{
GROWTH AND INFLATION: ESTIMATION OF THRESHOLD POINT FOR NEPAL
}

\author{
Tara Prasad Bhusal* and Sajana Silpakar**
}

\begin{abstract}
This article is primarily meant to estimate threshold level of inflation in Nepal using annual data for the period 1975-2010. The threshold value of inflation is found to be 6\% for Nepal. Beyond that level of inflation rate, higher or lower than the threshold value, the economic growth can be jeopardized. Looking specifically at Nepal's economic and inflation performance, the less than robust link between the two variables is not surprising, given the current structure of the economy and factors which influence inflation.
\end{abstract}

Key Words: Growth, Inflation, Granger Causality, Threshold

\section{INTRODUCTION}

Recent economic research work has explored different aspects of the relationship between inflation and economic growth over the last many years. One aspect of this research work is to identify the breakpoints after which inflation is harmful to economic growth. Some studies find a threshold rate of inflation, above which the effect of inflation on growth is significant and negative, while below that level, it is insignificant and positive.

However, as the empirical evidence by recent research work differs substantially across the countries. There is no consensus over the point after which the inflation is deterrent to economic growth. Fischer (1993) used a spline regression and found a negative relationship at all levels of Inflation. Barro (1996) found inflation harmful to growth but his findings were driven by the observations where inflation exceeded $20 \%$. Below that, the point estimate was negative but statistically insignificant. Bruno and Easterly (1998) found that countries ith annual inflation above $40 \%$ grows significantly lower than countries with inflation rates below $40 \%$. Using the most advanced econometric techniques, Khan and Senhadji (2001) found 1\% threshold level of inflation for industrialized countries, which means above $1 \%$ it would have negative effects on growth. On the contrary, Burdekin (2000) found a threshold level of $8 \%$ for the said countries. This result is also consistent with the findings of Sarel (1996) which tested for a structural break and found that inflation is negatively related to growth after $8 \%$. However, the point estimate for inflation below $8 \%$ was found positive but statistically insignificant. Similarly, Ghosh and Phillips (1998) used 2.2\%

*Mr. Bhusal is Lecturer, Department of Economics, Patan Multiple Campus, T.U.
* Ms. Silpakar is Faculty Member, Khwopa College, Bhaktapur 
threshold level of inflation in the analysis for industrialized countries while Judson and Orphanides (1996) assumed 10\% threshold level without empirical testing. In the same way, Khan and Senhadji (2001) found 11\% threshold level of inflation for developing countries (including India \& Nepal); again below 11\% the inflation-growth effect is positive but insignificant. Another study found a threshold level of $3 \%$ or less for developing countries (including India and Pakistan) (Burdekin, 2000)

The review of literature reveals prevalence of significant variations among the results of empirical studies, as the effects of inflation on growth are quite different across the countries. Moreover, the divergence of results was quite wide in case of empirical studies which concentrated on estimation of threshold rate of inflation for individual countries. For example, Singh (2003) found no threshold level for India whereas Mubarik (2005) found a threshold rate of inflation as high as 9\% for Pakistan. Some of the explanatory factors for significant variations in the results of above studies may include data problems, methodological issues and estimation problems, etc. A number of studies followed linear approaches while others used non-linear techniques for the estimation of threshold rate of inflation for countries. Similarly, Khan and Senhadji (2001) used non-linear approach and found stark differences in threshold level of inflation between developing and industrialized countries. Mubarik (2005) also used the same approach for the estimation of threshold effect for Pakistan. The main objective of this article is to explore the relationship between inflation and economic growth and to find the threshold level of inflation for Nepal.

\section{DATA AND METHODOLOGY}

Most of the studies conducted on the subject used cross sectional data \& panel data with the coverage of a large number of countries. For example, Khan and Senhadji (2001) and Ahmed and Burdekin (2009) used cross sectional data and covered many countries in the analysis. Researchers prefer to use cross sectional data because single country typically lacks the variety of inflation experiences necessary to determine if there is an inflation/growth relationship (Judson and Orphanides, 1996). However, Bruno and Easterly (1998) reported that any cross-sectional relationship between inflation and growth loses significance when data from countries with $40 \%$ or more inflation are excluded from the analysis. Similarly, Fischer (1993) and Barro (1996) utilized panel data to take into consideration the time dimension of inflation and growth. There are a very few studies like Singh and Meguire (2003) and Mubarik (2005), which used time series data to estimate threshold rate of inflation for individual countries.

The current study also uses annual data for the period 1975 to 2010 for the estimation of threshold level of inflation for Nepal. Data source on consumer's price index (CPI) and Gross domestic product (GDP) are taken from different issues of Economic Surveys published by Government of Nepal and Nepal Rastra Bank of Nepal. 


\section{AN OVERVIEW OF ECONOMIC GROWTH AND INFLATION}

To understand the historical nature of the relationship between inflation and real GDP growth in Nepal more accurately, the samples covering 1975 to 2010 is grouped into five observations. Initially the range of the inflation is selected on the basis of the maximum and minimum levels of the inflation throughout the time series. First of all the average GDP growth are calculated on the basis of the subsequent levels of inflation. For example, the average GDP growth is calculated for the inflation level of the 3 and less than three, the GDP growth rates from 1975 to 2010 are calculated against each linear level of inflation. The trend of annual inflation and GDP growth rates of the period 1975-2010 is depicted in Figure1.

Figure 1: Annual Inflation and GDP Growth Rates (1975-2010)

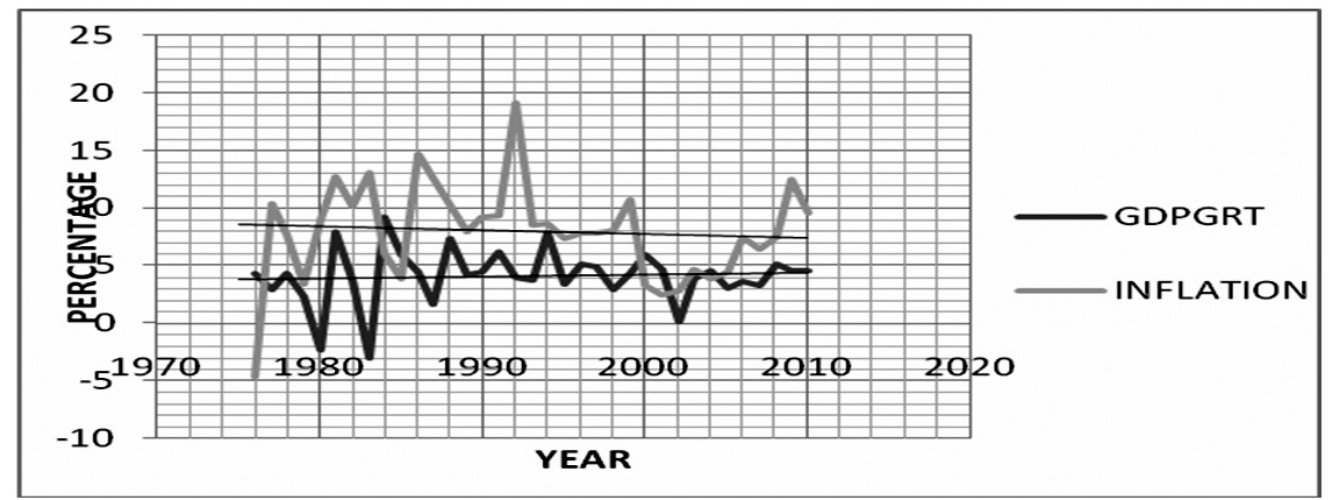

Source: Economic Survey, GON, Ministry of Finance (2011)

Again to understand the historical nature of the relationship between inflation and real GDP growth in the visual plot of GDP growth and inflation is shown in Figure 2.

Figure 2: Average growth of GDP and Linear Level of Inflation

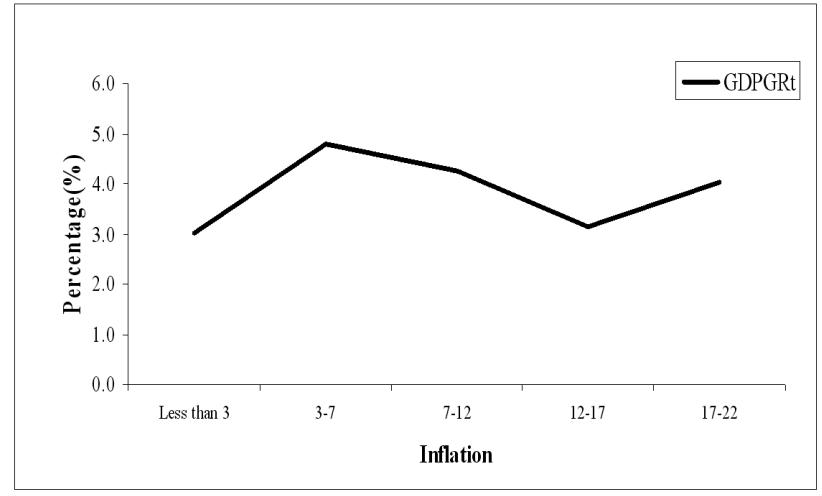

Source: Authors' calculation from data collected from Economic Survey 
The figure depicts that there is a positive relationship between inflation and Economic growth rate up to 7-12 percent which increases the growth rate and after that level of inflation rate the economic growth decreases.

\section{ESTIMATION OF THRESHOLD MODEL}

Before estimating the model, Granger Causality test is applied to measure the linear causation between inflation and economic growth. The results of the Granger Causality test are presented in the Tables 1 and 2.

Table 1: The Granger Causality Test of LNGDP and LNCPI (lag1)

\begin{tabular}{|l|l|l|l|}
\hline \multicolumn{5}{|l|}{ Pair wise Granger Causality Tests } \\
\hline Sample: 36 & Observations & F- Statistic & Prob. \\
\hline Lags: 1 & 34 & 0.24583 & 0.6235 \\
\hline Null Hypothesis: & 34 & 9.49512 & 0.0043 \\
\hline LNGDP does not Granger Cause LNCPI & 34 & &
\end{tabular}

Source: Authors' calculation

Table 2 : Granger causality test of LNGDP and LNCPI (lag 2)

\begin{tabular}{|l|l|l|l|}
\hline \multicolumn{4}{|l|}{ Pair wise Granger Causality Tests } \\
\hline Sample: 36 \\
\hline Lags: 2 & Observations & F- Statistic & Prob. \\
\hline Null Hypothesis: & 34 & 0.05672 & 0.9450 \\
\hline LNGDP does not Granger Cause CPI & 34 & 4.80551 & 0.0161 \\
\hline LNCPI does not Granger Cause LNGDP
\end{tabular}

Source: Authors' calculation

The results of Granger causality suggest that there is only one way causal relationship between the real GDP and CPI that is CPI Granger causes the real GDP. The null hypothesis that "LNGDP does not Granger causes LNCPI" is cannot be rejected in 0.05 level of significance in both lag 1 and lag 2. So, there is only one way causal relationship between the GDP and CPI. 
Test statistics in Table 1 and 2 shows that the null hypothesis is rejected only for inflation causes GDP, which means that inflation is causing GDP growth. The causality between two variables is unidirectional. The second null hypothesis of output growth causes inflation is not rejected at 5-10 percent level of significance, which proves that there is no feedback from output growth to inflation. This result helps in the choice of dependent and independent variable for the threshold model specification. The natural logarithm of GDP (LNGDP) and natural logarithm of CPI (LNCPI) are respectively used as proxies for economic growth and inflation. The causal relationship between the real GDP and CPI that is LNGDP and LNCPI is explored through the Granger Causality Test.

The results of Granger causality suggest that there is only one way causal relationship between the real GDP and CPI, that is, CPI Granger causes the real GDP. The null hypothesis that "LNGDP does not Granger cause LNCPI" cannot be rejected at 0.05 level of significance in both lag 1 and lag 2. So, there is only one way causal relationship between the GDP and CPI.

For determining the threshold value of inflation in case of Nepal, the ordinary least square method is used. The following table gives the exact value of the threshold inflation level and also shows the impact of that inflation level on economic growth by estimating equation (i). The estimated value of $\mathrm{R} 2$ is taken into consideration by estimating equation (i) for the threshold level of inflation considering $\mathrm{K}=1$ to $\mathrm{K}=8$. However, considering the value of the $\mathrm{R}^{2}$, the estimated results have been shown in the table is for $\mathrm{K}$ values ranging from 5 percent to 8 percent. As reviewed in the previous part, in this approach, the threshold value is one that maximizes the value of $R^{2}$.

For the estimation of threshold of inflation, this paper also follows nonlinear approach used by various researchers, including Mubarik (2005).

The following equation is estimated for the period 1975 to 2010 for Nepal.

$$
\text { GDPGRT }=\beta 0+\beta 1 \mathrm{INF}+\beta 2 \mathrm{D}(\mathrm{INF}-\mathrm{K})+\mathrm{Ui} .
$$

where, GDPGRT= GDP growth rate , INF= Inflation, $\mathrm{K}=$ the threshold level of inflation. It is the rate of inflation at which structural break occurs and $\mathrm{Ui}=$ the random error term which represents measurement error in the explanatory variables.

The dummy variable $\mathrm{D}$ is defined in the following way:

$$
\begin{gathered}
D=1 \text { if INF }>K \\
=0 \text { if } \mathrm{INF} \leq \mathrm{K}
\end{gathered}
$$


$\mathrm{K}$ denotes the threshold level of inflation with the property of inflation rate being below inflation, the variables are all equal to zero and the effect of inflation is estimated by the coefficient on inflation: ( $\beta 1)$. But when the inflation rate is at higher levels, the coefficient on inflation is the sum of beta coefficients $(\beta 1+\beta 2)$. In order to locate the threshold level of inflation we first allow for one break by varying the inflation rate from a low level to a high level. Standard statistical tools are used to identify the threshold point and check the reliability of the regression estimates. By estimating regressions for different values of $\mathrm{K}$, this is chosen in an ascending order from low to high. Here $\mathrm{K}$ is chosen from $5 \%$ to $8 \%$. The optimal value $\mathrm{K}$ is obtained by finding the value that maximizes the $\mathrm{R} 2$ from the respective regressions.

This also implies that the optimal threshold level is that which minimizes the residual sum of squares (RSS). The empirical results are given in Table 3.

Table 3: Estimation of Model using OLS (Sample 1975 - 2010): Dependent Variable: GDPGRT

\begin{tabular}{|c|c|c|c|c|c|c|}
\hline $\mathrm{K}$ & Variable & Coefficient & Standard Error & t-statistic & Probability & R-Squared \\
\hline \multirow{3}{*}{$5 \%$} & INF & 0.087864 & \begin{tabular}{|l|}
0.276967 \\
\end{tabular} & 0.317235 & 0.7532 & \multirow{3}{*}{0.010735} \\
\hline & D(INF-K) & -0.170646 & 0.358748 & -0.475671 & 0.6376 & \\
\hline & C & 4.001654 & 1.205311 & 3.320018 & 0.0023 & \\
\hline \multirow{3}{*}{$5.5 \%$} & INF & 0.098189 & 0.258106 & 0.38042 & 0.7062 & \multirow{3}{*}{0.013506} \\
\hline & D(INF-K) & -0.195568 & 0.349019 & -0.560336 & 0.5793 & \\
\hline & C & 3.935875 & 1.205135 & 3.265921 & 0.0027 & \\
\hline \multirow{3}{*}{$6 \%$} & INF & 0.101438 & 0.238022 & 0.426171 & 0.6729 & \multirow{3}{*}{0.016232} \\
\hline & D(INF-K) & -0.21242 & 0.33556 & -0.633031 & 0.5314 & \\
\hline & C & 3.885243 & 1.198796 & 3.240953 & 0.0028 & \\
\hline \multirow{3}{*}{$6.5 \%$} & INF & 0.054136 & 0.216447 & 0.250112 & 0.8042 & \multirow{3}{*}{0.01043} \\
\hline & D(INF-K) & -0.144723 & 0.31095 & -0.465423 & 0.6449 & \\
\hline & C & 4.010189 & 1.204105 & 3.330681 & 0.0022 & \\
\hline \multirow{3}{*}{$7 \%$} & INF & 0.05837 & 0.203238 & 0.323942 & 0.7482 & \multirow{3}{*}{0.013936} \\
\hline & \begin{tabular}{|l} 
D(INF-K) \\
\end{tabular} & -0.179409 & 0.313445 & -0.572377 & 0.5712 & \\
\hline & C & 3.950463 & 1.178796 & 3.35127 & 0.0021 & \\
\hline \multirow{3}{*}{$8 \%$} & INF & 0.03357 & 0.171767 & 0.19544 & 0.8463 & \multirow{3}{*}{0.011337} \\
\hline & D(INF-K) & -0.142668 & 0.288068 & -0.49526 & 0.6239 & \\
\hline & C & 4.033606 & 1.146914 & 3.51692 & 0.0014 & \\
\hline
\end{tabular}

Source: Authors' Calculation

From the estimated results, it is observable that at low threshold inflation levels $(K<6)$ there is a statistically insignificant relationship (at 5 percent level) between the dummy 
of threshold level of inflation and economic growth. As $\mathrm{K}$ increases to 6 percent a statistically significant relationship (at 5 percent level) is observed between economic growth and the dummy of threshold level of inflation rate. So, the threshold level of inflation rate is 6 percent where the value of $\mathrm{R}^{2}$ is maximized that is RSS is minimized (Bhusal, 2009). While inflation below this threshold level has no significant effect on economic growth, inflation rates above it have a significant effect on economic growth. Therefore, the empirical analysis suggests that if inflation rate is above 6-percent, then the economic growth performance of Nepal might experience a jeopardized situation.

\section{CONCLUSION}

The study reveals the positive relationship between the inflation and the economic growth. The inflation and economic growth are one way related to each other, there is one way causal relationship from inflation to economic growth but not from economic growth to inflation. The monetary policy of fiscal year 2012/13 of Nepal has estimated the inflation rate 7 percent for Nepal, where as the threshold value of inflation is found to be $6 \%$ for Nepal. Beyond that level of inflation rate (higher or lower than the threshold value) the economic growth can be jeopardized. Although, it is quite hard to derive policy implications on the basis of this study only, however, it can safely be concluded that policies that stabilizes the inflation to the certain threshold level matters for the long run economic growth. Nepal Rastra Bank could apply expansionary monetary policy for supporting economic growth until the inflation rate does not exceed the threshold level $(6 \%)$ and contractionary monetary policy after the inflation rate exceed that threshold level or till inflation under control.

\section{References}

Ahmed, S. \& Burdekin (2009). Inflation and economic growth in Bangladesh: 1981-2005. Policy Analysis Unit (PAU). Working Paper Series: WP 0604.

Barro , R . (1996). Inflation and growth. Federal Reserve Bank of St. Louis Review, 78, 153-169.

Bhusal, T.P. (2009). Basic Econometrics. Kathmandu: Ayam Publication,

Bruno, M., \& Easterly, W. (1998). Inflation crises and long-run growth. Journal of Monetary Economics, 41, 3-26.

Fischer, S. (1993). The role of macroeconomic factors in growth. National Bureau of Economic Research (NBER) working paper No: 4565.

Ghosh, A., \& Phillips, S. (1998). Warning: Inflation may be harmful to your growth. IMF Staff Papers, 45(4), 672-710.

Government of Nepal, Ministry of Finance (2011). Economic Survey, Kathmandu. Author

Judson, R., \& Orphanides, A. (1996). Inflation, volatility and growth .Board of Governors of the Federal Reserve System, Finance and economics discussion series, 96/19 
Khan, M. S., and Senhadji, A.S. (2000).Threshold effects in the relationship between inflation and growth. IMF Working Paper.

Meguire, P.G., \& Singh, D.G. (1985). Macroeconomic determinants of growth: cross- country evidence. Journal of monetary Economics, 16(2), 141-163.

Mubarik, Y. A. (2005). Inflation and growth: an estimate of the threshold level of inflation in Pakistan. State Bank of Pakistan Research Bulletin, 1 (1),

Nepal Rastra Bank (2007). Inflation in Nepal. Baluwatar, Kathmandu: Research Department.

Sarel, M. (1996). Nonlinear effects of inflation on economic growth. IMF Working Paper WP/95/56.

\section{APPENDIX}

Table 1: Data of CPI and GDP

(Base year: 1994/95) Rs. in Million

\begin{tabular}{|ccc|ccc|}
\hline Year & $\begin{array}{c}\text { Consumer's Price } \\
\text { Index (CPI) }\end{array}$ & $\begin{array}{c}\text { Real Gross } \\
\text { Domestic Product } \\
(\text { RGDP) }\end{array}$ & Year & $\begin{array}{c}\text { Consumer's } \\
\text { Price Index (CPI) }\end{array}$ & $\begin{array}{c}\text { Real Gross Domestic } \\
\text { Product (RGDP) }\end{array}$ \\
\hline 1975 & 16.6 & 91538.2 & 1999 & 141.0 & 249661.6 \\
1976 & 15.9 & 95565.75 & 2000 & 145.7 & 265140.4 \\
1977 & 17.6 & 98432.71 & 2001 & 149.3 & 277867.1 \\
1978 & 19.0 & 102763.5 & 2002 & 153.6 & 278145 \\
1979 & 19.7 & 105230 & 2003 & 161.0 & 288993 \\
1980 & 21.5 & 102809.9 & 2004 & 167.4 & 302575.4 \\
1981 & 24.4 & 111342.8 & 2005 & 174.9 & 311955.2 \\
1982 & 27.0 & 115574.2 & 2006 & 188.4 & 323497.6 \\
1983 & 30.8 & 112106.8 & 2007 & 201.0 & 334173.3 \\
1984 & 32.8 & 122981.4 & 2008 & 216.4 & 351884.3 \\
1985 & 34.1 & 130483 & 2009 & 245.1 & 368422.6 \\
1986 & 39.5 & 136485.3 & 2010 & 269.8 & 385586.2 \\
1987 & 44.8 & 138806 & 2000 & 145.7 & 265140.4 \\
1988 & 49.6 & 149493.8 & 2001 & 149.3 & 277867.1 \\
1989 & 53.7 & 155922.1 & 2002 & 153.6 & 278145 \\
1990 & 58.9 & 163094.4 & 2003 & 161.0 & 288993 \\
1991 & 64.6 & 173532.6 & 2004 & 167.4 & 302575.4 \\
1992 & 78.3 & 180647.5 & 2005 & 174.9 & 311955.2 \\
1993 & 85.2 & 187511.6 & 2006 & 188.4 & 323497.6 \\
1994 & 92.9 & 202887.7 & 2007 & 201.0 & 334173.3 \\
1995 & 100.0 & 209988.8 & 2008 & 216.4 & 351884.3 \\
1996 & 108.1 & 221118.5 & 2009 & 245.1 & 368422.6 \\
1997 & 116.9 & 232174.3 & 2010 & 269.8 & 385586.2 \\
1998 & 126.6 & 239139.5 & & & \\
\hline
\end{tabular}

Source: Government of Nepal, Ministry of Finance, Economic Survey, Various Issues 